\title{
Safety of artemether-lumefantrine exposure in first trimester of pregnancy: an observational cohort
}

\author{
Dominic Mosha ${ }^{1,2^{*}}$, Festo Mazuguni ${ }^{1}$, Sigilbert Mrema' ${ }^{1}$ Esperanca Sevene ${ }^{3}$, Salim Abdulla ${ }^{1}$ and Blaise Genton ${ }^{2,4}$
}

\begin{abstract}
Background: There is limited data available regarding safety profile of artemisinins in early pregnancy. They are, therefore, not recommended by WHO as a first-line treatment for malaria in first trimester due to associated embryo-foetal toxicity in animal studies. The study assessed birth outcome among pregnant women inadvertently exposed to artemether-lumefantrine (AL) during first trimester in comparison to those of women exposed to other anti-malarial drugs or no drug at all during the same period of pregnancy.

Methods: Pregnant women with gestational age $<20$ weeks were recruited from Maternal Health clinics or from monthly house visits (demographic surveillance), and followed prospectively until delivery.

Results: 2167 pregnant women were recruited and 1783 (82.3\%) completed the study until delivery. 319 (17.9\%) used anti-malarials in first trimester, of whom 172 (53.9\%) used (AL), 78 (24.4\%) quinine, 66 (20.7\%) sulphadoxine-pyrimethamine (SP) and 11 (3.4\%) amodiaquine. Quinine exposure in first trimester was associated with an increased risk of miscarriage/stillbirth (OR 2.5; 1.3-5.1) and premature birth (OR 2.6; 1.3-5.3) as opposed to AL with (OR 1.4; 0.8-2.5) for miscarriage/stillbirth and (OR 0.9; 0.5-1.8) for preterm birth. Congenital anomalies were identified in 4 exposure groups namely AL only (1/164[0.6\%]), quinine only (1/70[1.4\%]), SP (2/66[3.0\%]), and non-anti-malarial exposure group (19/1464[1.3\%]).

Conclusion: Exposure to AL in first trimester was more common than to any other anti-malarial drugs. Quinine exposure was associated with adverse pregnancy outcomes which was not the case following other anti-malarial intake. Since AL and quinine were used according to their availability rather than to disease severity, it is likely that the effect observed was related to the drug and not to the disease itself. Even with this caveat, a change of policy from quinine to AL for the treatment of uncomplicated malaria during the whole pregnancy period could be already envisaged.
\end{abstract}

Keywords: Pregnancy, Safety, Artemether-lumefantrine, Exposure

\section{Background}

Over $60 \%$ of all pregnancies globally are at risk of malaria and more than 32 million are in sub-Sahara Africa [1]. Malaria infection is associated with high maternal and perinatal mortality in tropical and subtropical regions [2]. Severe maternal anaemia, intrauterine growth retardation, intrauterine death, stillbirth, premature delivery and low birth-weight are some of the reported substantial direct risks of malaria in pregnancy [2,3]. Although malaria in pregnancy is a serious public health

\footnotetext{
* Correspondence: dfmosha@hotmail.com

'Ifakara Health Institute, Rufiji HDSS, P.O Box 40, Rufiji, Tanzania

${ }^{2}$ Swiss Tropical and Public Health Institute, University of Basel, Basel, Switzerland

Full list of author information is available at the end of the article
}

problem, there is limited information available regarding safety profile of most of licensed anti-malarial in pregnancy because pregnant women are routinely not involved in clinical trials related to drug development for fear of harming the women and or developing foetus [4].

Artemisinin-based combination therapy (ACT) is the most effective drug combination for Plasmodium falciparum malaria and has been recommended by the World Health Organization (WHO) as a treatment of choice for the treatment of P. falciparum malaria [5]. ACT is only recommended in pregnancy during second and third trimester, but not in first trimester, unless they are the only treatment available, or if the patient's life is threatened. Safety concerns of artemisinins in first 
trimester are the associated risks of visceral and skeletal anomalies following animal studies in early stage of pregnancy [6,7]. Two previous small-scale studies assessing Zambian and Sudanese pregnant women exposed to artemisinin during first trimester could not find any association between drug exposure and maternal or birth adverse outcomes [8,9]. However, evidence is still scarce to ensure safety of ACT during first trimester.

Artemether-lumefantrine (AL) (20 mg and $120 \mathrm{mg}$, respectively) (Coartem $\odot$, Novartis Pharm AG) is one of the most popular and efficacious fixed dose of ACT which is currently available [10]. AL was introduced in Tanzania as a first-line therapy for malaria in 2006 to replace sulphadoxine-pyrimethamine (SP) [11]. Inadvertent exposure to artemisinin during first trimester of pregnancy is possible due to its high availability at a subsidized cost in both private and public health facilities in the country $[12,13]$. Furthermore, self-treatment of malaria without consulting a trained professional is common in sub-Sahara Africa; indeed, 70\% of malaria episodes in rural Africa and 50\% in urban areas are self-treated cases [14]. It is, therefore, important to take advantage of the latter to extend the margin safety information of artemisinin compounds in pregnancy by evaluating maternal and birth outcomes of inadvertently AL exposure to women in their first trimester.

There is increasing evidence supporting efficacy, safety and tolerability of ACT, which outweigh the advantages of quinine in treating malaria $[15,16]$. Despite its reactogenicity profile and several reports of resistant strains of $P$ falciparum $[17,18]$, quinine remains the only recommended drug for treating both uncomplicated and complicated $P$ falciparum malaria during first trimester of pregnancy $[5,11]$. The present study aims at assessing the maternal and birth outcomes in pregnant women who were inadvertently exposed to AL during first trimester in comparison to those of women exposed to other anti-malarial drugs or no drug at all during the same period of pregnancy using two Health Demographic Surveillance System (HDSS) platforms in Tanzania.

\section{Methods}

\section{Study area}

The study was conducted in Rufiji and Kigoma HDSS in Tanzania. Rufiji HDSS is in a rural setting while Kigoma HDSS is in an urban one, both areas have moderate to high malaria transmission intensity [19]. The study involved a total of 22 health facilities in the two HDSS sites. There was no clinical interventional research activity in the area during the study period.

\section{Study design}

The study enrolled pregnant women with gestational age of 20 weeks and below between April 2012 and
March 2013. Only women residing in HDSS were eligible for the study. They were recruited from Reproductive and Child Health $(\mathrm{RCH})$ clinic during their routine visits and from the community through monthly round-based house visits. The set-up of HDSS allows identification of pregnancy status in women of childbearing age through routine HDSS quarterly census. On the day of enrolment, participants were interviewed for obstetrics and previous medical history including history of chronic illness or disease, use of alcohol and smoking. Important laboratory test such as maternal haemoglobin level, screening for HIV and syphilis were performed. Use of any antimalarial during first trimester of the presenting pregnancy was the key question during interview. Information regarding the reported drug used by a participant was verified by assessing patient's medical log in the attended health facility, prescription sheet and maternal $\mathrm{RCH}$ card. Assessment of RCH card and patient's medical log were also carried out for participants who reported no drug intake. In case of discordance between the facility medical log and what the participant had reported regarding the used medicine, participant's information was considered the truth after further interview to verify specifications of the said medicine, whether it was used or not. Participants who had inadvertently used AL for malaria treatment in first trimester were compared with pregnant women who were treated with either quinine (Qn), sulphadoxine-pyrimethamine (SP), amodiaquine or women who had not used anti-malarial drug(s) at all during the same period of pregnancy. Thus, women were not randomized but grouped to the study arm according to their anti-malarial exposure history in first trimester.

Women were followed on monthly basis until delivery to monitor pregnancy and birth outcomes. The assessed pregnancy outcome included maternal mortality, spontaneous abortion (pregnancy lose $\leq 28$ weeks of gestation), ectopic gestation, stillbirth and live birth. Birth outcome included birth weight, maturity status at birth [estimated from the last normal menstrual period (LNMP), or fundal height examination, when the LNMP was unknown] and presence of congenital anomalies. All newborns were assessed for congenital abnormalities post-delivery by a study clinician or health facility midwife. Screening for congenital abnormalities was performed under the guidance of a specific developed checklist. The screening was limited to identify external abnormalities regardless of the degree of severity. No examination was performed to determine neurological score for sensory or motor patterns.

\section{Primary endpoint}

Primary endpoints of the study were pregnancy and baby outcomes. Pregnancy outcome included miscarriage, stillbirth or live birth whereas baby outcome included birth weight and prematurity status at birth. Stillbirth 
was defined as a baby born with no signs of life at or after 28 weeks of gestation. Low birth weight was defined as a birth weight below 2,500 grams and premature was defined as birth before 37 weeks of gestational age.

\section{Statistical analysis}

STATA $^{\bullet} 12.0$ (Stata Corporation, College Station, Texas, USA) was used for data analysis. Numerical variables were summarized into mean and standard deviation. Categorical variables were summarized using cross tabulation to estimate different proportion. The effect of demographic and pregnancy characteristics on primary endpoint of the study was assessed by bivariate analysis. Explanatory variables were included in the multivariate analysis if the variable had $\mathrm{p}$-value $<0.2$ in bivariate analysis. Logistic regression model were used to estimate the odds ratio (OR) for the associated between binary pregnancy outcomes (birth outcome, birth weight and birth maturity status) and medicine exposure. Two sided Wald test P-values are presented.

\section{Ethics}

Ethical approval was granted by the Ifakara Health Institute (IHI) ethical review board and the National Institute for Medical Research (NIMR) ethical committee. Written informed consent was obtained from all participants.

\section{Results}

A total of 2,167 pregnant women were enrolled in the study and 1,783 (82.3\%) were followed until delivery (Figure 1). 19.2\% (342) were recruited from the community through house visit and $80.8 \%$ (1441) from the facility during their routine $\mathrm{RCH}$ clinic visits. 602 (33.8\%) women were recruited in first trimester of pregnancy with mean gestational age of 10.5 [standard deviation (SD) 2.6] and 1181 (66.2\%) during the first half of second trimester of pregnancy with mean gestation age of 16.9 (1.5). 559 (31.4\%) were primigavidae, 336 (18.8\%) secundigravidae and 888 (49.8\%) were multigravidae with gravidity of 3 and above. Important demographic and clinical characteristics are summarized in Table 1.

\section{Drug exposure}

319 (17.9\%) women used anti-malarial in first trimester of pregnancy because of a morbid episode. 164 (51.4\%) used AL only, 70 (21.9\%) quinine only, 8 (2.5\%) both AL and quinine, 66 (20.7\%) SP and 11 (3.4\%) amodiaquine. At least $88 \%$ of study women used three group of drugs that are in antenatal intervention as recommended by the Ministry of Health [11] namely, anthelminthic, sulphadoxine-pyrimethamine (SP) for intermittent preventive treatment of malaria (IPTp) and iron and folic acid supplementation. Anthelminthic and IPTp-SP are prescribed in second and third trimester of pregnancy. 1579 (88.6\%) used anthelminthic (mebendazole), 1626 (91.2\%) used iron and folic acid supplementation and $1636(91.8 \%)$ used at least one dose of IPTp-SP.

\section{Pregnancy outcome and anti-malarial exposure}

Among 1783 deliveries, there were 5 maternal deaths that occurred within 24 hours, three were due to postpartum haemorrhage and the remaining two each was secondary to eclampsia and disseminated intravascular coagulopathy (DIC), respectively. Pregnancy outcomes included 44 (2.5\%) abortions, 62 (3.5\%) stillbirth and 1677 (94.1\%) live births. Baby outcomes included 81 (4.8\%)

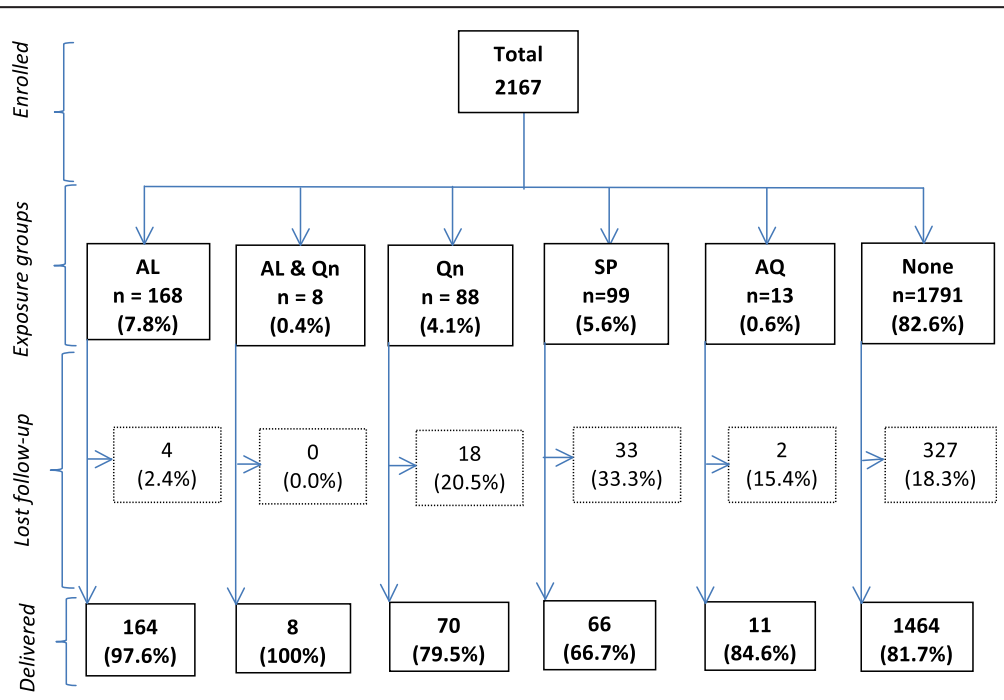

Figure 1 Flow chart of participants in the study. $A L=$ Artemether-lumefantrine; $Q n=$ Quinine; $S P=$ Sulphadoxine-pyrimethamine; $\mathrm{AQ}=$ Amodiaquine; None $=$ No anti-malarial. 
Table 1 Characteristics of pregnant women enrolled in the study

\begin{tabular}{|c|c|c|c|}
\hline Characteristics & $\begin{array}{l}\text { First trimester } \\
\qquad n=602\end{array}$ & $\begin{array}{l}\text { First half of second trimester } \\
\qquad n=1181\end{array}$ & $\begin{array}{l}\text { All trimesters } \\
n=1783\end{array}$ \\
\hline Mean age, (years)* & $25.7(6.8 ; 14-49)$ & $25.9(6.7 ; 13-46)$ & $25.8(6.8 ; 13-49)$ \\
\hline Mean BMI* & $23.2(3.9 ; 14.2-39.6)$ & $23.3(3.6 ; 14.0-42.5)$ & $23.4(3.7 ; 14.0-42.5)$ \\
\hline Mean gestational age, $($ weeks)* & $10.5(2.6 ; 3-12)$ & $16.9(1.5 ; 13-20)$ & $14.8(3.7 ; 3-20)$ \\
\hline \multicolumn{4}{|l|}{ Gravidity $^{\#}$} \\
\hline Primigravidae & $182(30.0)$ & 377 (31.9) & $559(31.4)$ \\
\hline Secundigravidae & $109(18.0)$ & $227(19.2)$ & $336(18.8)$ \\
\hline $3-4$ pregnancies & $180(29.6)$ & $315(26.7)$ & $495(27.8)$ \\
\hline$\geq 5$ pregnancies & $131(21.4)$ & $262(22.2)$ & $393(22.0)$ \\
\hline \multicolumn{4}{|l|}{ Recruited sites ${ }^{\#}$} \\
\hline Health facility & $468(22.3)$ & $973(82.4)$ & $1441(80.8)$ \\
\hline Home & $134(77.7)$ & $208(17.6)$ & $342(19.2)$ \\
\hline Drinking alcohol ${ }^{\#}$ & $14(2.7)$ & $27(2.3)$ & $41(2.3)$ \\
\hline Smoking cigarette & $5(0.8)$ & $2(0.2)$ & $7(0.4)$ \\
\hline Haemoglobin level $(\mathrm{g} / \mathrm{dl})^{*}$ & $10.8(1.5 ; 5.0-14.6)$ & $10.7(1.5 ; 5.4-14.9)$ & $10.7(1.5 ; 5.0-14.9)$ \\
\hline \multicolumn{4}{|l|}{ HIV status" } \\
\hline Negative & $533(88.5)$ & $1086(92.0)$ & $1619(90.8)$ \\
\hline Positive & $18(3.0)$ & $46(3.9)$ & $64(3.6)$ \\
\hline No results & $51(8.5)$ & $49(4.1)$ & $100(5.6)$ \\
\hline \multicolumn{4}{|l|}{ Syphilis test ${ }^{\#}$} \\
\hline Negative & $521(86.5)$ & $1082(91.6)$ & 1603 (89.9) \\
\hline Positive & $12(2.0)$ & $15(1.3)$ & $27(1.5)$ \\
\hline No results & $69(11.5)$ & $84(7.1)$ & 153 (8.6) \\
\hline
\end{tabular}

Abbreviation: $\mathrm{BMI}=$ Body Mass Index.

*Represents data presented in mean, (standard deviation [SD]; range).

"Represent data presented in number (\%).

Table 2 Pregnancy and baby outcomes in relation to anti-malarial exposure status during first trimester

\begin{tabular}{|c|c|c|c|c|c|c|}
\hline Pregnancy outcome & $\begin{array}{l}\text { AL only } \\
164(\%)\end{array}$ & $\begin{array}{c}\text { AL \& Quinine } \\
8(\%)\end{array}$ & $\begin{array}{c}\text { Quinine only } \\
70(\%)\end{array}$ & $\begin{array}{c}\text { SP } \\
66(\%) \\
\end{array}$ & $\begin{array}{c}\text { Amodiaquine } \\
11(\%)\end{array}$ & $\begin{array}{c}\text { None } \\
1464(\%) \\
\end{array}$ \\
\hline Abortion & $5(3.0)$ & $2(25.0)$ & $3(4.3)$ & $0(0.0)$ & $0(0.0)$ & $34(2.3)$ \\
\hline Stillbirth & $6(3.7)$ & $0(0.0)$ & $5(7.1)$ & $2(3.0)$ & $0(0.0)$ & $49(3.3)$ \\
\hline Live birth & $153(93.3)$ & $6(75.0)$ & $62(88.6)$ & $64(97.0)$ & $11(100)$ & $1381(94.3)$ \\
\hline \multicolumn{7}{|l|}{ Birth maturity* } \\
\hline Preterm birth & $8(5.2)$ & $2(33.3)$ & $8(12.9)$ & $7(10.9)$ & $0(0.0)$ & $88(6.4)$ \\
\hline Full term birth & $145(94.8)$ & $4(66.7)$ & $54(87.1)$ & $57(89.1)$ & $11(100)$ & 1293 (93.6) \\
\hline \multicolumn{7}{|l|}{ Birth weight* } \\
\hline Low birth weight & $8(5.2)$ & $1(16.7)$ & $1(1.6)$ & $2(3.1)$ & $0(0.0)$ & $69(5.0)$ \\
\hline Normal birth weight & $145(94.8)$ & $5(83.3)$ & $61(98.4)$ & $62(96.9)$ & $11(100)$ & $1312(95.0)$ \\
\hline Congenital anomalies & $1(0.6)$ & $0(0.0)$ & $1(1.4)$ & $2(3.0)$ & $0(0.0)$ & $19(1.3)$ \\
\hline
\end{tabular}

Abbreviation: $\mathrm{AL}=$ Artemether-lumefantrine; $\mathrm{SP}=$ Sulphadoxine-pyrimethamine.

*Excluded abortion and stillbirth outcomes. 
Table 3 Pregnancy outcomes in relation to anti-malarial exposure status in first trimester

\begin{tabular}{|c|c|c|c|c|c|c|}
\hline \multirow{2}{*}{$\begin{array}{l}\text { Variables } \\
\text { Birth outcome }\end{array}$} & \multicolumn{2}{|c|}{ Outcomes } & \multirow{2}{*}{$\begin{array}{l}\text { Crude OR } \\
(95 \% \mathrm{Cl})\end{array}$} & \multirow[t]{2}{*}{$\mathrm{P}^{\mu}$} & \multirow{2}{*}{$\begin{array}{l}\text { Adjusted OR } \\
\quad(95 \% \mathrm{Cl})\end{array}$} & \multirow[t]{2}{*}{$\mathrm{P}^{\mu}$} \\
\hline & $\begin{array}{c}\mathrm{MC} / \mathrm{SB} \\
\mathrm{n}(\%)\end{array}$ & $\begin{array}{l}\text { Live birth } \\
\text { n (\%) }\end{array}$ & & & & \\
\hline \multicolumn{7}{|l|}{ AL exposure } \\
\hline Yes & $13(12.3)$ & $159(9.5)$ & $1.3(0.7-2.4)$ & 0.348 & $1.4(0.8-2.5)$ & 0.295 \\
\hline No & $93(87.7)$ & $1518(90.5)$ & & & & \\
\hline \multicolumn{7}{|l|}{ Quinine exposure } \\
\hline Yes & $10(9.4)$ & $68(4.1)$ & $2.5(1.2-4.9)$ & 0.011 & $2.5(1.3-5.1)$ & 0.009 \\
\hline No & $96(90.6)$ & $1609(95.9)$ & & & & \\
\hline \multicolumn{7}{|l|}{ SP exposure } \\
\hline Yes & $2(1.9)$ & $64(3.8)$ & $0.5(0.1-2.0)$ & 0.318 & $0.5(0.1-2.0)$ & 0.312 \\
\hline No & $104(98.1)$ & $1613(96.2)$ & & & & \\
\hline \multicolumn{7}{|l|}{ Amodiaquine exposure } \\
\hline Yes & $0(0.0)$ & $11(0.7)$ & $-(0)$ & - & $-(0)$ & - \\
\hline No & $106(100)$ & $1666(99.3)$ & & & & \\
\hline \multicolumn{7}{|l|}{ No anti-malarial exposure } \\
\hline Yes & $83(78.3)$ & $1380(82.3)$ & $0.8(0.5-1.3)$ & 0.301 & $0.8(0.5-1.2)$ & 0.260 \\
\hline No & $23(21.7)$ & $297(17.7)$ & & & & \\
\hline \multirow[t]{2}{*}{ Birth weight (grams) } & $<2500$ & $\geq \mathbf{2 5 0 0}$ & & & & \\
\hline & n (\%) & n (\%) & & & & \\
\hline \multicolumn{7}{|l|}{ AL exposure } \\
\hline Yes & $9(11.1)$ & $150(9.4)$ & $1.2(0.6-2.5)$ & 0.608 & $1.2(0.6-2.5)$ & 0.573 \\
\hline No & $72(88.9)$ & $1446(90.6)$ & & & & \\
\hline \multicolumn{7}{|l|}{ Quinine exposure } \\
\hline Yes & $2(2.5)$ & $66(4.1)$ & $0.6(0.1-2.4)$ & 0.463 & $0.6(0.1-2.4)$ & 0.461 \\
\hline No & $79(97.5)$ & $1530(95.9)$ & & & & \\
\hline \multicolumn{7}{|l|}{ SP exposure } \\
\hline Yes & $2(2.5)$ & $62(3.9)$ & $0.6(0.2-2.6)$ & 0.520 & $0.7(0.2-3.0)$ & 0.639 \\
\hline No & 79 (97.5) & $1534(96.1)$ & & & & \\
\hline \multicolumn{7}{|l|}{ Amodiaquine exposure } \\
\hline Yes & $0(0.0)$ & $11(0.7)$ & $-(0)$ & - & $-(0)$ & - \\
\hline No & $100(100)$ & $1585(99.3)$ & & & & \\
\hline \multicolumn{7}{|l|}{ No anti-malarial exposure } \\
\hline Yes & $69(85.2)$ & $1311(82.1)$ & $1.3(0.7-2.3)$ & 0.485 & $1.2(0.6-2.3)$ & 0.564 \\
\hline No & $12(14.8)$ & $285(17.9)$ & & & & \\
\hline \multirow[t]{2}{*}{ Maturity status at birth } & Preterm & Term & & & & \\
\hline & n (\%) & n (\%) & & & & \\
\hline \multicolumn{7}{|l|}{ AL exposure } \\
\hline Yes & $10(8.9)$ & $149(9.5)$ & $0.9(0.5-1.8)$ & 0.812 & $0.9(0.5-1.8)$ & 0.865 \\
\hline No & $103(91.1)$ & $1415(90.5)$ & & & & \\
\hline \multicolumn{7}{|l|}{ Quinine exposure } \\
\hline Yes & $10(8.9)$ & $58(3.7)$ & $2.5(1.3-5.1)$ & 0.010 & $2.6(1.3-5.3)$ & 0.007 \\
\hline No & $103(91.1)$ & $1506(96.3)$ & & & & \\
\hline
\end{tabular}


Table 3 Pregnancy outcomes in relation to anti-malarial exposure status in first trimester (Continued)

\begin{tabular}{|c|c|c|c|c|c|c|}
\hline \multicolumn{7}{|c|}{ SP exposure } \\
\hline Yes & $7(6.2)$ & 57 (3.6) & $1.7(0.8-3.9)$ & 0.177 & $1.8(0.8-4.1)$ & 0.160 \\
\hline No & $106(93.8)$ & 1507 (96.4) & & & & \\
\hline \multicolumn{7}{|c|}{ Amodiaquine exposure } \\
\hline Yes & $0(0.0)$ & $11(0.7)$ & $-(0)$ & - & $-(0)$ & - \\
\hline No & $113(100)$ & 1553 (99.3) & & & & \\
\hline \multicolumn{7}{|c|}{ No anti-malarial exposure } \\
\hline Yes & $88(77.9)$ & $1292(82.6)$ & $0.7(0.5-1.2)$ & 0.205 & $0.7(0.5-1.1)$ & 0.168 \\
\hline No & $25(22.1)$ & $272(17.4)$ & & & & \\
\hline
\end{tabular}

Abbreviations: $\mathrm{AL}=$ Artemether-lumefantrine; $\mathrm{MC}=$ Miscarriage; $\mathrm{SB}=$ Stillbirth; $\mathrm{SP}=$ Sulphadoxine-pyrimethamine.

$\mathrm{RR}=$ Relative Risk; $\mathrm{Cl}=$ Confidence Interval.

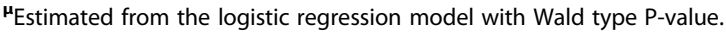

adjusted for age and parity.

low birth weight babies and 113 (6.7\%) premature births. $23(1.3 \%)$ of the newborns were identified to have congenital anomalies at birth including, polydactyl 17 (73.9\%), club foot $2(8.7 \%)$, genital defect $2(8.7 \%)$, spina bifida $1(4.3 \%)$ and cardiac defect 1 (4.3\%). Congenital anomalies were identified in four exposed groups namely AL only $(1[0.6 \%]$ of 164), quinine only (1 [1.4\%] of 70), SP (2 [3.0\%] of 66), and non-anti-malarial exposed group (19 of [1.3\%] of 1464). The median gestational age of anti-malarial exposure in the four exposure groups with congenital anomalies was $9(6-10)$ weeks. Table 2 summarizes pregnancy outcomes parameters in relation to anti-malarial exposure status in first trimester.

Quinine exposure during first trimester was associated with an increased risk of miscarriage/stillbirth (adjusted OR 2.5 ; 95\%CI $1.3-5.1 ; \mathrm{p}=0.009$ ) and premature birth (adjusted OR 2.6; 95\%CI $1.3-5.3$; p = 0.007) as opposed to AL, SP and amodiaquine exposure which were not associated with increased risk of either miscarriage/stillbirth, low birth weight or premature birth [see details in Table 3].

Maternal age and parity were assessed to determine their effect on pregnancy outcome as potential confounders of the drug effect. Increase of maternal age in years was associated with $5 \%$ decreased risk of low birth weight (OR 0.95; p = 0.009), 5\% increased risk of miscarriage/stillbirth (OR 1.05; $\mathrm{p}=0.001)$, and $3 \%$ increased risk of preterm birth (OR 1.03; $\mathrm{p}=0.016)$. Multigravidae had $50 \%$ decreased risk of low birth weight (OR 0.5; $\mathrm{p}=0.006), 60 \%$ increased risk of miscarriage/stillbirth (OR 1.6; $\mathrm{p}=0.048$ ), and $30 \%$ increased risk of preterm birth (OR 1.3; $\mathrm{p}=0.099$ ) compared to primigravidae.

\section{Discussion}

The study findings provide further evidence on the safety profile of AL use in early pregnancy to treat malaria. It differs from previous first trimester artemisinins derivatives safety studies $[8,9]$ by having a larger sample size and a broader comparative exposure group. Also, the low mean gestational age at enrolment improves accuracy of drug exposure history, and thus reduces recall bias. It also increases the chances of identifying adverse pregnancy outcomes which commonly occurs during early stage of pregnancy, such as abortion [20].

Although AL is not recommended as first-line treatment for malaria during first trimester of pregnancy, it was used by $54 \%$ of women in this indication. Exposure to $\mathrm{AL}$ in first trimester was twofold higher than quinine, the drug of choice for malaria treatment during first trimester in Tanzania [11]. This observation suggests that $\mathrm{AL}$ is a popular drug. It reflects its high accessibility in most of the health facilities and by drug vendors in the country $[12,13]$. In practice, quinine was frequently outof-stock and its replacement could easily take several weeks, particularly in public health facilities. The latter may explain why the efforts of study team to remind clinicians in study health facilities about contraindication of AL in first trimester had little effect. Since shortage of drugs is common in resource-limited settings [21,22], inadvertent or voluntary exposure to contraindicated drugs is inevitable. Limited access to quinine may also explain the observed high SP and amodiaquine exposure, drugs which are currently not recommended for treating malarial illness [5].

Quinine exposure was associated with a two-fold increased risk of miscarriage, stillbirth and preterm birth. The harmful effect of quinine during pregnancy has been known for a long time. Its abortive properties in relation to the induction of uterine contractions have long been reported by Maxwell [23]. The strength and prolongation of these contractions were reported to be dose dependent. A randomized control trial in Uganda showed oral quinine to have a two-fold increased incidence of adverse effects compared to AL among pregnant women treated for uncomplicated malaria in second and third trimesters. There were nearly two-fold increases 
in intrauterine foetal deaths in the quinine group than in the AL one, although the numbers were low. On the other hand, there was no difference in proportions of spontaneous abortions in the two study groups [16].

In the present study, these adverse pregnancy outcomes were not observed following AL, SP or amodiaquine exposure, which suggests that the deleterious effect of quinine was more related to the drug itself, rather than to the malaria episode. This is supported by the observation made by fieldworkers that quinine was not given to a particular group of women because of more severe disease, but just because AL was more readily accessible on the shelf of the health facility. Also, all women took quinine tablets, and not intravenous doses, which suggest a similar degree of severity of the disease in women who took quinine and AL. However, since it was not a proper randomized double-blind controlled trial, it is not possible to formally exclude a selection bias that would lead to different effects of the malaria disease itself. Whatever is the cause, the magnitude of the adverse effects associated with quinine exposure is alarming, when considering that this drug is viewed at present as the safest anti-malarial drug in first trimester. There is a remote possibility of a deleterious effect of AL on the foetus, and hence on infant development, that could not be assessed at this stage in the study. We hope to be able to definitely exclude an adverse consequence of $\mathrm{AL}$ exposure during pregnancy on the infant when analysing the results of the 12-month follow-up of the offsprings. Precise information on neurological scores, including motor and sensory patterns, should assist policy decisions after careful analysis of the time of antimalarial exposure. The preliminary results of the first infant cohort are encouraging.

The observed prevalence of $1.3 \%$ congenital anomaly in the present study is lower than the global prevalence (3.0\%) estimated by WHO [24]. No national figures of congenital anomalies are available for comparison in Tanzania. There are obvious limitations to screen for external anomalies only during the neonatal period: This may lead to an underestimation of the true prevalence of congenital abnormalities, which may appear later in life. Congenital anomalies was twice in the non-anti-malarial exposed group compared to AL exposed group (1.3\% vs $0.6 \%)$. Polydactyly was the most reported congenital anomaly (74\%), but it is believed to be genetically determined rather than triggered by external exposure [25]. In animal studies, umbilical hernia has been reported to be associated with artemisinin exposure during pregnancy [6]. The present study had limitation to assess occurrence of umbilical hernia since the newborns were screened only once at the time of delivery. At this time, hernias may hardly present, and cannot, therefore, be identified. Also, umbilical hernia is commonly observed in most parts of Africa and is not viewed as an abnormality, it is often not brought to medical attention unless it manifests itself with complications such as intestinal obstruction [26,27].

\section{Conclusion}

Exposure to $\mathrm{AL}$ in first trimester was more common than to any other anti-malarial drugs. Quinine exposure was associated with adverse pregnancy outcome, which was not the case for other anti-malarials. Since AL and quinine were used according to their availability rather than to disease severity, it is likely that the effect observed was related to the drug, and not to the disease itself. More information of developmental milestone up to 12 months is needed to rule out any adverse effect on infancy as a result of AL exposure in first trimester. Even with this caveat, a change of policy from quinine to $\mathrm{AL}$ for the treatment of uncomplicated malaria during the whole pregnancy period could be already envisaged.

\section{Competing interests}

BG has received in the past a research grant from Novartis Pharma to work on the effect of artemether-lumefantrine introduction on child mortality and malaria transmission in Tanzania. Novartis Pharma had no involvement in the present project.

\section{Authors' contributions}

The study was designed by DM and BG, assisted by ES and SA. Enrolment and follow-up of participants in the field was coordinated by DM and SM. FM was responsible for data entry and analysis. DM and BG wrote the first draft of the manuscript. All authors participated in data interpretation, review and approved the final manuscript.

\section{Acknowledgements}

We thank the pregnant women for their cooperation and all staff involved in the study. Special thanks are given to Advocatus Kakorozya, Amri Shamte, Warren Temba, Nathan Gakwandi, Essau Gharika, Matrida Lihenye, Kahema Irema, Athumani Mzuyu and Kusudi Bakari of Rufiji and Kigoma HDSS.

\section{Financial support}

The study was co-funded by the Ifakara Health Institute $(I \mathrm{HI})$ and the European and Developing Countries Trial Partnership through the Malaria in Pregnancy Prevention Alternative Drugs project (EDCTP MiPPAD: IP.2007.31080.002).

\section{Author details}

'Ifakara Health Institute, Rufiji HDSS, P.O Box 40, Rufiji, Tanzania. ${ }^{2}$ Swiss Tropical and Public Health Institute, University of Basel, Basel, Switzerland. ${ }^{3}$ Universidade Eduardo Mondlane, Faculdade de Medicina, Manhica Health Research Centre, Maputo, Mozambique. ${ }^{4}$ Department of Ambulatory Care and Community Medicine \& Division of Infectious Diseases, University Hospital, Lausanne, Switzerland.

Received: 12 March 2014 Accepted: 22 May 2014

Published: 27 May 2014

\section{References}

1. Dellicour S, Tatem AJ, Guerra CA, Snow RW, ter Kuile FO: Quantifying the number of pregnancies at risk of malaria in 2007: a demographic study. PLoS Med 2010, 7:e1000221.

2. Desai M, ter Kuile FO, Nosten F, McGready R, Asamoa K, Brabin B, Newman RD: Epidemiology and burden of malaria in pregnancy. Lancet Infect Dis 2007, 7:93-104.

3. Steketee RW, Nahlen BL, Parise ME, Menendez C: The burden of malaria in pregnancy in malaria-endemic areas. Am J Trop Med Hyg 2001, 64:28-35. 
4. CFDER: Reviewer guidance evaluating the risks of drug exposure in human pregnancies. USA: Food and Drug Administration; 2005.

5. WHO: Guidelines for the treatment of malaria: second edition. Geneva: World Health Organization; 2010.

6. White TE, Clark RL: Sensitive periods for developmental toxicity of orally administered artesunate in the rat. Birth Defects Res B Dev Reprod Toxicol 2008, 83:407-417.

7. WHO: Assessment of the safety of artemisinin compounds in pregnancy: report of two informal consultations convened in 2006. Geneva: World Health Organization; 2007.

8. Adam I, Elhassan EM, Omer EM, Abdulla MA, Mahgoub HM, Adam GK: Safety of artemisinins during early pregnancy, assessed in 62 Sudanese women. Ann Trop Med Parasitol 2009, 103:205-210.

9. Manyando C, Mkandawire R, Puma L, Sinkala M, Mpabalwani E, Njunju E, Gomes M, Ribeiro I, Walter V, Virtanen M, Schlienger R, Cousin M, Chipimo M, Sullivan FM: Safety of artemether-lumefantrine in pregnant women with malaria: results of a prospective cohort study in Zambia. Malar J 2010, 9:249.

10. Lefevre G, Marrast AC, Grueninger H: Novartis Malaria Initiative: best practice example of pharmaceutical industry's engagement in the fight against malaria. Ann N Y Acad Sci 2011, 1222:19-29.

11. Ministry of Health of Tanzania: National guideline for malaria diagnosis and treatment 2005. Tanzania: National Malaria Control Programme; 2006.

12. Mbwasi R, Mlaki W: Increasing access to medicines in Tanzania. Lancet 2008, 372:205-206.

13. Rutta E, Kibassa B, McKinnon B, Liana J, Mbwasi R, Mlaki W, Embrey M, Gabra M, Shekalaghe E, Kimatta S, Sillo H: Increasing access to subsidized artemisinin-based combination therapy through accredited drug dispensing outlets in Tanzania. Health Res Policy Syst 2011, 9:22.

14. McCombie SC: Treatment seeking for malaria: a review of recent research. Soc Sci Med 1996, 43:933-945.

15. Dondorp AM, Fanello Cl, Hendriksen IC, Gomes E, Seni A, Chhaganlal KD, Bojang K, Olaosebikan R, Anunobi N, Maitland K, Kivaya E, Agbenyega T, Nguah SB, Evans J, Gesase S, Kahabuka C, Mtove G, Nadjm B, Deen J, Mwanga-Amumpaire J, Nansumba M, Karema C, Umulisa N, Uwimana A, Mokuolu OA, Adedoyin OT, Johnson WB, Tshefu AK, Onyamboko MA, Sakulthaew T, Ngum WP, Silamut K, Stepniewska K, Woodrow CJ, Bethell D, Wills B, Oneko M, Peto TE, von Seidlein L, Day NP, White NJ, Aquamat group: Artesunate versus quinine in the treatment of severe falciparum malaria in African children (AQUAMAT): an open-label, randomised trial. Lancet 2010, 376:1647-1657.

16. Piola P, Nabasumba C, Turyakira E, Dhorda M, Lindegardh $N$, Nyehangane $D$, Snounou G, Ashley EA, McGready R, Nosten F, Guerin PJ: Efficacy and safety of artemether-lumefantrine compared with quinine in pregnant women with uncomplicated Plasmodium falciparum malaria: an open-label, randomised, non-inferiority trial. Lancet Infect Dis 2010, 10:762-769.

17. Okombo J, Ohuma E, Picot S, Nzila A: Update on genetic markers of quinine resistance in Plasmodium falciparum. Mol Biochem Parasitol 2011 177:77-82.

18. Parker D, Lerdprom R, Srisatjarak W, Yan G, Sattabongkot J, Wood J, Sirichaisinthop J, Cui L: Longitudinal in vitro surveillance of Plasmodium falciparum sensitivity to common anti-malarials in Thailand between 1994 and 2010. Malar J 2012, 11:290.

19. Statistics TNBo: Preliminary results of the 2011-12 Tanzania HIV/Aida and malaria indicator survey (THMIS). NBS 2012, 24-27.

20. Everett $C$ : Incidence and outcome of bleeding before the 20th week of pregnancy: prospective study from general practice. BMJ 1997, 315:32-34.

21. Lufesi NN, Andrew M, Aursnes I: Deficient supplies of drugs for life threatening diseases in an African community. BMC Health Serv Res 2007, 7:86.

22. Twaweza: Stock out or in stock? Acess to medicines in Tanzania. Twaweza 2013, 5:1-4.

23. Maxwell JP: The use of quinine during pregnancy, labour, and the puerperium. Trans R Soc Trop Med Hyg 1908, 1:229-235.

24. WHO: Congenital anomalies. Geneva: World Health Organization; 2012.

25. Cheng B, Dong Y, He L, Tang W, Yu H, Lu J, Xu L, Zheng B, Li K, Xiao C: Crossed polydactyly type I caused by a point mutation in the GLI3 gene in a large Chinese pedigree. J Clin Lab Anal 2006, 20:133-138.
26. David O, David M: The prevalence, spontaneous resolution, and parent's attitudes towards umbilical hernia coexisting in Nigerian children presenting with other surgical pathology. Ann Pediatr Surg 2009, 5:16-20.

27. Meier DE, OlaOlorun DA, Omodele RA, Nkor SK, Tarpley JL: Incidence of umbilical hernia in African children: redefinition of "normal" and reevaluation of indications for repair. World J Surg 2001, 25:645-648.

doi:10.1186/1475-2875-13-197

Cite this article as: Mosha et al: Safety of artemether-lumefantrine exposure in first trimester of pregnancy: an observational cohort. Malaria Journal 2014 13:197.

\section{Submit your next manuscript to BioMed Central and take full advantage of:}

- Convenient online submission

- Thorough peer review

- No space constraints or color figure charges

- Immediate publication on acceptance

- Inclusion in PubMed, CAS, Scopus and Google Scholar

- Research which is freely available for redistribution

Submit your manuscript at www.biomedcentral.com/submit
C BioMed Central 